\title{
As características dos indivíduos são determinantes para as desigualdades regionais em educação no Brasil? Uma análise para os anos de 2004 e 2014
}

\author{
Waleska de Fátima Monteiro \\ Professora da Universidade Federal de Goiás - UFG \\ Email:wfmonteiro05@gmail.com
}

Resumo: Em um contexto de desigualdade econômica regional e educacional, estudos que abordam essa temática têm ganhado importância no meio acadêmico. A contribuição deste trabalho está em alinhar os debates sobre estes dois temas no cenário brasileiro e responder a seguinte pergunta: a distribuição espacial de características dos indivíduos e suas famílias, que reconhecidamente afetam a educação das crianças e jovens, são determinantes importantes nas desigualdades regionais em educação que são observadas no Brasil? Usando a metodologia proposta por Juhn, Murphy e Pierce (1993), com dados da PNAD para os anos de 2004 e 2014, para jovens entre 14 e 17 anos, encontramos que o principal determinante da desigualdade é a diferença nos parâmetros dos jovens e seus familiares, ou seja, como as características individuais são transformadas ou convertidas em educação, são os principais fatores para desigualdade. Porém, outras características individuais como escolaridade dos pais ou jovens estudar em escola particular, por exemplo, contribuem para a redução da desigualdade. Além disso, nota-se que a desigualdade educacional entre as regiões vem reduzindo ao longo do tempo.

Palavras-chave: Desigualdade, educação e decomposição JMP

Abstract: In a context of regional educational and economic inequality, studies this inequality have gained importance in academia. The contribution of this work is to align the debate on these two issues in the Brazilian scenario and answer the following question: the spatial distribution characteristics of individuals and their families, known to affect the education of children and youth, are important determinants of high regional inequalities in education that are observed in Brazil? Using the methodology proposed by Juhn, Murphy and Pierce (1993), with PNAD data for the years 2004 and 2014, youth between 14 and 17 years, found that the main determinant of inequality is the response characteristics (difference in parameters) of young people and their families, that is, as these characteristics are transformed or converted into education. However, other individual characteristics such as mother and father with higher level of education, for example, contribute to reducing inequality and youth studying in a private school. Furthermore, educational inequality between regions is reduced over time.

Key words: Inequality, Education, and JMP decomposition.

JEL Code: 124, 125, J24 


\section{INTRODUÇÃO}

Entender como a distribuição espacial das características dos indivíduos juntamente com as características de seus familiares, que reconhecidamente afetam a educação das crianças e jovens, é um tópico de extrema importância para compreendermos a existência e perpetuação das desigualdades regionais em educação que são observadas no Brasil. A relevância deste tema está não apenas nas diferenças da distribuição dessas características na população, mas também nas diferenças regionais e mecanismos que interagem com tais características e resultam em maior ou menor nível educacional, e principalmente, seus efeitos para a desigualdade dentro das regiões.

Para compreender o que pode ser feito para melhorar a qualidade do sistema educacional, se faz necessário encontrar fatores que possam determinar o que influencia nesta desigualdade. A importância dessa análise é verificada na elaboração de políticas públicas mais eficientes, dada à escassez de recursos e a relevância do processo educacional no desenvolvimento socioeconômico do país. Desta maneira, dada à heterogeneidade do território brasileiro, estudos regionalizados são importantes por destacar características, que em um contexto mais geral, podem ficar negligenciadas.

No Brasil, tanto no nível primário como secundário, a educação é altamente descentralizada, e essa descentralização fica evidente quando avaliado os gastos e formas de gestão do sistema de ensino que são heterogêneos, não só entre estados como também entre municípios. As desigualdades educacionais refletem desigualdades regionais mais amplas (Castro, 2000 \& Rigotti, 2001) e os estados e municípios mais pobres são justamente aqueles que mais deveriam elevar o nível educacional de suas populações para alcançar os patamares das áreas com melhor desempenho (BELTRÃO et al 2002).

Reduzir tal desigualdade é meta de várias iniciativas de políticas públicas, no entanto, não é um trabalho simples, uma vez que existem fatores não controlados pelos gestores. O que motiva esse assunto é a ideia de que a convergência regional não irá ocorrer espontaneamente em um período curto de tempo. Com isso, torna-se importante avaliar quais são os fatore que contribuem para a redução da desigualdade educacional entre as regiões.

O debate sobre convergência educacional parte do princípio de análise de infraestrutura (gastos), de qualificação dos professores, do ambiente social, assim como, das características individuais dos jovens e seus familiares. Os autores Barros e Mendonça (2000) e Medeiros e Oliveira (2013) enfatizam que a educação por ser uma atividade complexa, possui uma lista de determinantes de desigualdade muito extensa. Contudo, é possível organizá-la em grupos: O primeiro grupo seria a escola, que inclui as características dos professores, da administração da escola, da infraestrutura das instalações, técnicas de ensino, e etc. O segundo seria o ambiente social, que tenta abarcar fatores não escolares da sociedade que afetam de modo relevante à educação, como, por exemplo, transporte, segurança e valores culturais relacionados à educação e ao trabalho, etc. E por fim, as características individuais, que remete a educação dos pais, renda, composição familiar, atributos como raça, gênero, e etc. Essa divisão é analítica e não exaustiva, uma vez que há grande interação entre eles, bem como interseção 
p. 59 - As características dos indivíduos são determinantes para as desigualdades regionais em educação no Brasil? Uma análise para os anos de 2004 e 2014

também. Barros e Mendonça (2000) ainda constata a importância de avaliar estes grupos separado e/ou simultaneamente, uma vez que eles impactam diretamente no desempenho educacional dos jovens.

De acordo com Machado e Gonzaga (2007), no Brasil, há uma vasta literatura empírica sobre as relações existentes entre escolaridade das crianças e as características individuais dos familiares desses jovens, bem como à complementaridade entre esses fatores. Um dos primeiros trabalhos que afere o impacto das características individuais no desempenho educacional dos jovens foi realizado em 1966 por Coleman. O autor mostra que estudantes com as mesmas características familiares e mesmo perfil socioeconômico, apresentariam o mesmo nível de alfabetização, mesmo que estudassem em escolas diferentes, quando comparados a outros dois estudantes que apresentassem características diferentes (familiar e socioeconômico), porém estudando na mesma escola (COLEMAN, 1966). Contudo, há poucos trabalhos na literatura que examinam a desigualdade educacional entre as regiões, analisando características individuais.

Com o intuito de expandir esse debate na literatura, este trabalho analisará quais são os determinantes da desigualdade educacional regional no Brasil, e principalmente verificar se fatores não escolares, que afetam a educação, é elemento importante para desigualdade educacional que são observadas nas regiões do Brasil. Para alcançar o objetivo proposto, este trabalho apresentará além desse breve introdução, mais quatro seções divididas da seguinte forma: a seção a seguir apresenta um conciso debate da literatura, a terceira seção apresenta a metodologia e construção dos dados, a quarta apresenta a discussão dos resultados, e por fim, a conclusão deste trabalho.

\section{FUNDAMENTAÇÃO TEÓRICA}

O rápido crescimento econômico do período que vai do segundo pós-guerra até 1980 levou o Brasil a ingressar no grupo das dez maiores economias do mundo. Ao longo desse período não faltaram programas de desenvolvimento, discursos e plataformas políticas que deixassem de proclamar a centralidade da educação no desenvolvimento do país e, eventualmente, no aperfeiçoamento da democracia (Plank, 1996). Contudo, a evolução educacional esteve sempre aquém do crescimento econômico.

Ainda hoje, o Brasil apresenta indicadores educacionais abaixo dos padrões internacionais e o mais preocupante é o fato de que o subinvestimento em capital humano é tanto mais acentuado quanto mais pobre é a região analisada. Estudos como os de Medeiros e Oliveira (2013), Amadeo et al (1995), e Berhman (1995) indicam que, qualquer que seja o indicador de desempenho educacional utilizado, o Brasil sempre encontra-se em situação inferior à dos países do mundo ou da América Latina com nível de renda similar. Esse fato pode ser observado com clareza no último relatório do PISA (2015), em que o escore médio dos estudantes brasileiros apresentou valor significativamente inferior à média dos estudantes dos países membros da OCDE. O relatório também aponta as diferenças regionais como um dos determinantes para o baixo desempenho e relata a necessidade de debates que verifiquem os principais fatores dessa disparidade e auxiliem na equiparação educacional dos jovens brasileiros. 
Permanecendo nesse contexto Medeiros e Oliveira (2013) salientam que a maior parte do debate sobre desigualdade educacional entre regiões tem foco no sistema de ensino, mais exatamente, na contratação ou qualificação de professores e, em menor escala, em infraestrutura. Resultado disso é a ênfase dada aos pisos salariais de professores e aos equipamentos escolares. Colocando de forma sintética, o debate centra-se na equiparação de escolas como mecanismo para a convergência regional.

Outros estudos apontam que as disparidades dos níveis educacionais entre as regiões são causadas pela composição social da população de cada região. Um estudo pioneiro que mostra a composição social como fator para que os indicadores educacionais permaneçam baixos foi realizado por Barros e Lam (1993). Os autores destacam quatro características indesejáveis da educação no Brasil: 1ํ) o nível educacional médio da população é baixo; 2ํ) a educação está desigualmente distribuída; 3ㅇ) existe uma correlação alta entre as realizações educacionais das crianças e as de seus pais e avós, indicando a ausência de igualdade de oportunidades e 4ํ) há grandes disparidades regionais nas realizações educacionais das crianças. Segundo Barros et. al, (2001), parte dessas disparidades regionais podem ser explicadas pela composição social da população de cada região. Como a origem social afeta o nível educacional dos jovens, regiões com maiores proporções de pessoas vindas de famílias com características desvantajosas tendem a apresentar menores níveis educacionais. Contribuindo, portanto, para a perpetuação da desigualdade educacional entre as regiões.

Corroborando os resultados citados acima, Lam e Marteleto (2006) mostra em seu estudo que as decomposições regionais demonstram que a defasagem educacional das crianças do Nordeste, deve-se principalmente ao efeito negativo da baixa escolaridade dos pais. Com isso, é possível verificar a importância da origem social na determinação da educação. Barros e Mendonça (2000) já havia constatado que a escolaridade dos adultos apresenta correlação com os indicadores de desempenho educacional dos jovens da região Nordeste. O autor destaca que escolaridade dos adultos é, certamente, o fator com maior contribuição, capaz de explicar o desempenho educacional da região.

Em uma análise sobre a transmissão intergeracional e a desigualdade educacional entre as regiões, Gonçalves e França (2008), analisam os impactos regionais sobre o sistema educacional, e concluem que a reprodução da desigualdade é um círculo vicioso, uma vez que estados com renda mal distribuída têm sistemas educacionais piores e mais desiguais. Logo, filhos de famílias com baixa renda, tendem a reproduzir a desigualdade educacional de seus pais.

Ainda em relação à desigualdade educacional, Silva e Hasenbalg (2000), destacam que o Brasil mostra indicadores educacionais que apenas superam apenas alguns países da América Latina. No entanto, ainda que lenta, o país vem apresentado uma expansão educacional das últimas duas décadas. Os autores mostram que elevou o nível de instrução da população e diminuiu a desigualdade educacional entre regiões. Cerca de aproximadamente $60 \%$ dessa melhoria é devida à mudança nas condições de vida e à distribuição geográfica das famílias, decorrente da urbanização e da transição demográfica, devendo-se os $40 \%$ restantes às melhorias efetivas no desempenho do sistema educacional. 
p. 61 - As características dos indivíduos são determinantes para as desigualdades regionais em educação no Brasil? Uma análise para os anos de 2004 e 2014

A desigualdade educacional também foi objeto de estudo de De Castro (2009). O autor apresentou a evolução das desigualdades nas condições educacionais dos brasileiros, e conclui que quando se consideraram os aspectos regionais, a população da região Nordeste ficou em pior situação em quase todos os indicadores analisados, tais como hiato educacional, taxa de analfabetismo, taxa de frequência bruta à educação infantil e taxa média esperada de conclusão no ensino fundamental.

Verifica-se, portanto, na literatura, que a desigualdade educacional regional, pode ser afetada por diferentes fatores: educação dos pais, rendimento das famílias, morar em área urbana, e etc. Com o mesmo objetivo dos trabalhos citados, o presente estudo tenta analisar quais as características individuais contribuem para a desigualdade educacional entre as regiões brasileiras para jovens de 14 e 17 anos. Será explicado a seguir a base de dados e a metodologia utilizada para responder essas questões.

\section{DADOS}

Analisar a desigualdade educacional entre as regiões é um estudo complexo, uma vez que a educação ocorre não só no ambiente educacional, mas também em ambientes externos. Alguns estudos argumentam que tanto as escolas como outros fatores escolares não são os principais determinantes da desigualdade, quando analisado pelo lado da educação. Há evidência indicando que a origem social, identificada por meio de características pessoais e familiares, possui um peso maior no desempenho educacional de crianças e jovens (Alves et al 2007; Cesar et al 2001; Gonçalves e França, 2008), e isso é um dos principais determinantes das desigualdades educacionais no Brasil (SILVA e HASENBALG, 2000). E essa desigualdade aumenta com o envelhecimento das pessoas (BARROS et al 2001).

O presente estudo utilizará dados das PNAD's (Pesquisa Nacional por Amostra de Domicílio) dos anos de 2004 e 2014. A motivação pela escolha desses dados em detrimento de dados de proficiência se dá pelo fato de a PNAD levar em conta informações sobre jovens que não frequentam a escola, um grupo muito importante para as políticas educacionais, em particular para políticas de redução de desigualdades regionais.

Diante desses argumentos, para alcançar o objetivo proposto, nos concentraremos nas características individuais e familiares de jovens entre 14 e 17 anos. A variável dependente utilizada neste estudo será anos de estudos desses jovens, e para tal variável Medeiros e Oliveira (2013) salienta que ela não é um indicador suficiente da qualidade da educação, uma vez que contemplam informação muito limitada sobre a proficiência dos alunos. Contudo, para o Brasil, ela é o único indicador disponível para alcançar os propósitos deste estudo.

Já as características individuais consideradas na regressão linear como variáveis independentes para os jovens de 14 a 17 anos são: gênero (mulher $=1$ e homem $=0$ ), 
raça parda $($ pardo $=1$ e branco $/$ preto $=0)$, raça preto $(\text { preto }=1 \text { e branco } / \text { pardo }=0)^{1} \mathrm{e}$ natureza institucional ou dependência da escola (se estuda em escola privada $=1 \mathrm{e}$ pública $=0$ ); e para os pais dos jovens são: logaritmo da renda domiciliar per capita; idade; dummies de raça para a mãe; dummies de raça para o pai; dummies de nível escolaridade do pai e da mãe, dummy para mãe que trabalha 15 ou mais horas semanais; e controle das características geográficas do local de residência (zona rural igual = 1 e urbanas $=0$ ).

A partir das variáveis descritas acima, para verificar quais são as características individuais das famílias que contribuem para a desigualdade educacional entre as regiões, este trabalho utilizará a decomposição proposta por Juhn, Murphy e Pierce (1993), contudo, antes de entender a metodologia, se faz necessário mostrar porque o estado de São Paulo será usado como estado de referência² .

A decomposição empregada para essa mensuração consiste em estabelecer uma região de referência, estimar uma situação hipotética na qual todas as regiões teriam uma distribuição de características de ambiente social e escola semelhantes às da região de referência, mas manteriam suas distribuições de características individuais $e$ familiares tais como observadas para então contrastar as desigualdades regionais existentes com as estimadas nessa situação hipotética (MEDEIROS e OLIVEIRA, 2013). São Paulo foi escolhido como região de referência, uma vez que mesmo utilizando dados apenas do estado, as características individuais, neste caso a média de anos de estudo da sociedade, apresentam melhor resultado que as demais regiões.

O Gráfico 1 mostra a média de anos de estudo separada por região nos anos de 2004 e 2014. É possível perceber que o estado de São Paulo, apresenta maior média de estudos ao comparar com as demais regiões, inclusive quando comparada separadamente com o Distrito Federal ${ }^{3}$. Comparando o ano de 2004 com o de 2014, todas as regiões apresentam uma melhoria na média de anos de estudo. Mostrando, portanto, que o gasto com a educação básica no Brasil vem surtindo algum efeito.

As regiões Norte e Nordeste tiveram crescimento em anos de estudo maior que as demais regiões, uma vez que apresentaram em 10 anos, aumento de cerca de um ano na média de anos de estudo. Contudo, essa melhora não foi suficiente para alcançar, ou mesmo se aproximar, do estado de São Paulo. Em relação à média de São Paulo, que é de 8,7 anos de estudo em 2004 e 9,1 anos de estudo em 2014, a defasagem é de cerca de $22 \%$, quando comparada às regiões Norte e Nordeste no ano de 2004 , e cerca de $13 \%$ no ano de 2014. Este gráfico ilustra bem a desigualdade educacional entre as regiões, e principalmente, quão distante estão do estado de referência.

\footnotetext{
${ }^{1}$ Como o número de pessoas que se declararam com a raça amarela, indígena ou ignorada é pequeno e estatisticamente não significativo, decidimos desconsiderá-las, sem prejuízo aos resultados, conforme trabalho de SCHWARTZMAN (2007). Portanto foram mantidas apenas as raças, branca, preta e parda.

${ }^{2}$ Como São Paulo será utilizado como contrafactual deste estudo, a região sudeste será composta apenas pelos estados do Rio de Janeiro, Minas Gerais e Espírito Santo.

${ }^{3}$ O Distrito Federal, pelo elevado número de funcionários públicos, possui características distintas dos demais estados da região Centro-Oeste, e por isso, foi considerada separadamente.
} 
p. 63 - As características dos indivíduos são determinantes para as desigualdades regionais em educação no Brasil? Uma análise para os anos de 2004 e 2014

Gráfico 1- Média regional de anos de estudo

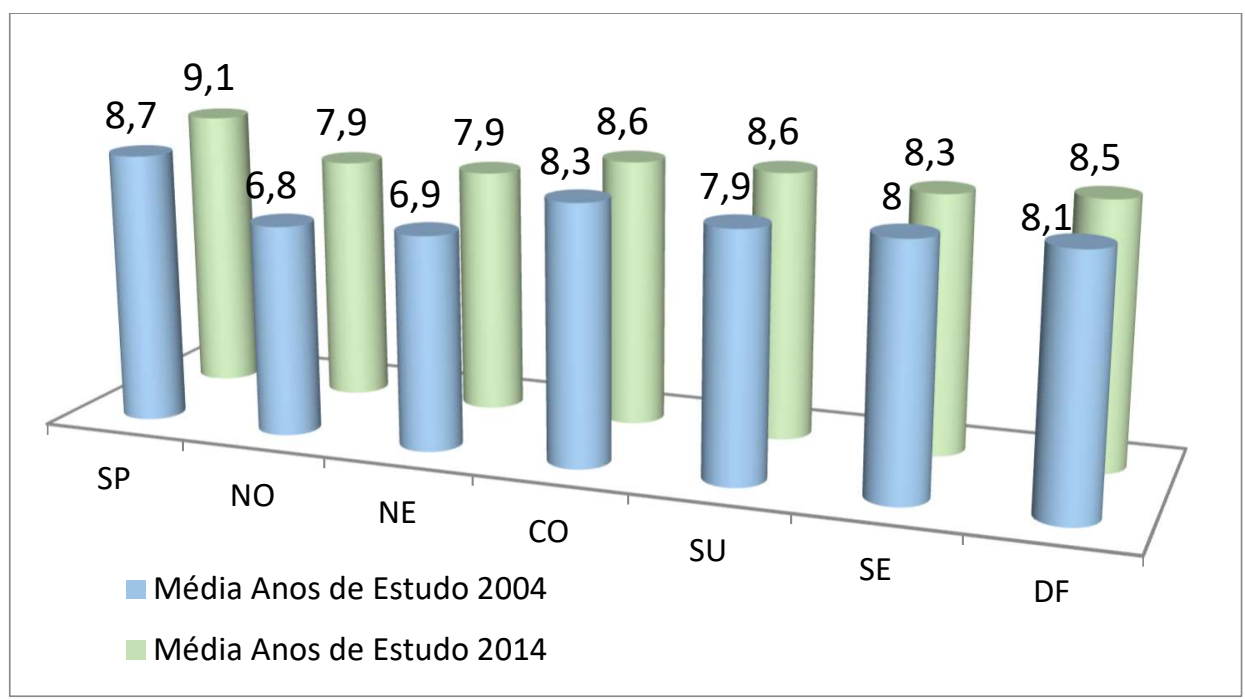

Fonte: Criado pela autora, a partir dos dados da PNAD 2004 e 2014.

Diante disso, será ilustrada a seguir a metodologia que permitirá entender quais são os principais fatores que contribuem para essa desigualdade. De modo mais específico, quais são as características individuais das famílias e dos jovens de 14 a 17 anos que contribuem para a persistência da desigualdade apresentada no gráfico acima.

\section{METODOLOGIA}

Identificar como características socioeconômicas e familiares podem impactar na desigualdade educacional, tem ganhado cada vez mais atenção na literatura (SCHWARTZMAN, 2007). Métodos de regressão são extremamente importantes nessas pesquisas e por vezes pesquisadores recorrem a modelos econômicos empíricos para identificar se há algum efeito imediato nas variáveis analisadas que podem causar alguma desigualdade educacional. Uma das abordagens utilizada para identificar tais causas é a técnica da decomposição contrafactual para verificar diferenças nas características e diferenças nos retornos a essas características entre grupos.

As decomposições utilizadas com maior frequência por pesquisadores são as de Blinder (1973) e Oaxaca (1973), bem como a decomposição proposta por Juhn, Murphy e Pierce (1993). A decomposição de Blinder (1973) e Oaxaca (1973) é útil em identificar as diferenças entre grupos com características possíveis de mensurar, tais como educação, experiência, estado civil e região geográfica, por exemplo. Essa decomposição é utilizada em regressões lineares que explicam as médias condicionais das variáveis independentes utilizadas nas regressões. Já a decomposição de Juhn, Murphy e Pierce (1993), é uma ampliação da técnica de decomposição de Oaxaca-Blinder. Os autores incorporaram à decomposição a posição que o indivíduo ocupa na distribuição residual, assim como a própria dispersão da distribuição residual (MONSUETO, 2003).

A principal inovação dessa metodologia é que ela permite operacionalizar decomposições para a distribuição educacional como um todo. Assim, com a simulação 
feita através de uma transformação preservadora da ordem, os autores viabilizaram a transposição da distribuição dos resíduos de um grupo para o outro. Logo, isso torna factível o estudo das disparidades das distribuições como um todo, assim como embute mais um termo na decomposição das diferenças, isto é, a distribuições dos resíduos (CRESPO, 2003).

Tendo em vista que o objetivo deste trabalho é identificar quais as características individuais contribuem para a desigualdade educacional entre as regiões, a metodologia proposta permitirá avaliar as variações entre grupos (as regiões) sujeitos a algum tipo de desigualdade, que neste caso será a desigualdade educacional. Além de avaliar as variações entre grupos, o uso dessa decomposição permitirá averiguar a distribuição dos resíduos, que desempenha papel importante, pois ele responde pelas características não observadas no presente estudo.

Diante disso, o método proposto faz uma decomposição que utiliza variáveis de controle (quantidade), coeficientes estimados (preços) e resíduos da regressão (não observados) para reconstruir sequencialmente a distribuição da desigualdade educacional entre as regiões. A partir desse procedimento é possível obter distribuições contrafactuais que nos permitem identificar a contribuição de cada um desses elementos na desigualdade educacional total. A seção a seguir apresentará a metodologia de Juhn, Murphy e Pierce (1993), detalhando os elementos que medem a desigualdade educacional total.

\section{a. Decomposição entre duas distribuições}

A decomposição de Juhn, Murphy e Pierce (1993) calcula a diferença entre duas distribuições (São Paulo e demais regiões, por exemplo) de resultados (nível educacional) com o objetivo de medir a desigualdade educacional entre as regiões do Brasil. Os coeficientes utilizados na decomposição para medir tal desigualdade serão estimados por Mínimos Quadrados Ordinários (MQO).

A metodologia permite decompor qualquer medida em três partes: quantidade, preço e não observáveis. A quantidade mede os efeitos de uma variação nas características observáveis dos indivíduos sobre a variação da diferença entre os grupos analisados em um determinado período de tempo. Já o preço mede a mudança no diferencial em decorrência de uma mudança na forma como o mercado valoriza os atributos observáveis, ou seja, avalia a diferença nos parâmetros. Enquanto que o terceiro mede o "efeito gap", ou seja, a diferença dos resíduos capta uma mudança na posição relativa dos indivíduos do grupo minoritário (avaliado) na distribuição do grupo majoritário (referência). Para melhor compreender essa decomposição, de acordo com Juhn, Murphy e Pierce (1993) e Foguel et al (2006), considere a equação abaixo:

$$
y_{i t}=X_{i t} \beta_{t}+u_{i t}
$$


p. 65 - As características dos indivíduos são determinantes para as desigualdades regionais em educação no Brasil? Uma análise para os anos de 2004 e 2014

em que $i$ representa o indivíduo, t o tempo e y o nível educacional do indivíduo, $X_{i t}$ o vetor de características observáveis do indivíduo ${ }^{4}, \beta_{t}$ o vetor de coeficientes para o período $t$, e $u_{i t}$ o termo de erro da regressão ${ }^{5}$. Para o presente estudo é útil avaliar esse resíduo como dois componentes: o primeiro composto por $\theta_{i t}$ sendo o percentil do indivíduo $i$ no tempo $t$ na distribuição residual e o segundo composto por $F_{t}\left(. \mid X_{i t}\right)$ sendo a distribuição acumulada condicional dos resíduos no tempo $t$. Por definição temos:

$$
u_{i t}=F_{t}^{-1}\left(\theta_{i t} \mid X_{i t}\right)
$$

em que $F_{t}^{-1}\left(\theta_{i t} \mid X_{i t}\right)$ é a função inversa de distribuição acumulada dos indivíduos com características $X_{i t}$ no ano $t$.

Conforme Juhn, Murphy e Pierce (1993), mudanças estruturais na desigualdade podem vir de três fontes: mudança na distribuição das características dos indivíduos, que neste caso é uma mudança na distribuição dos X's (raça dos filhos, renda da família, nível educacional dos pais, infraestrutura física da escola, característica dos professores, por exemplo), alteração no preço das habilidades observáveis, isto é, mudança nos parâmetros ( $\beta^{\prime}$ s) e mudança na distribuição dos resíduos.

Se definirmos $\bar{\beta}$ como o vetor de preços das características observáveis da regressão para todos os períodos conjuntamente e $\bar{F}_{t}\left(\theta_{i t} \mid X_{i t}\right)$ a distribuição condicional dos resíduos dessa regressão conjunta, podemos então, decompor o nível de desigualdade nos seguintes componentes:

$$
y_{i t}=X_{i t} \bar{\beta}+X_{i t}\left(\beta_{t}-\bar{\beta}\right)+\bar{F}^{-1}\left(\theta_{i t} \mid X_{i t}\right)+\left[F_{t}^{-1}\left(\theta_{i t} \mid X_{i t}\right)-\bar{F}^{-1}\left(\theta_{i t} \mid X_{i t}\right)\right]
$$

O primeiro termo capta o efeito das variáveis a preços fixos. O segundo termo capta os efeitos das variações de preços de habilidade para os X's observáveis fixos, e o termo final capta os efeitos de mudanças na distribuição residual.

A partir da equação (3) podemos simular a distribuição do nível educacional do indivíduo $i$ no período $t$ utilizando os $X^{\prime}$ s observados em $t$ e em um tempo fixo de referência $s$, porém mantendo constantes os preços e a distribuição dos resíduos, conforme a seguir:

$$
y_{i t}^{1}=X_{i t} \bar{\beta}_{S}+\bar{F}_{S}^{-1}\left(\theta_{i t} \mid X_{i t}\right)
$$

Verifica-se que tanto os preços como os resíduos estão fixos, portanto a distribuição de $y_{i t}^{1}$ só muda ao longo do tempo se os X's variarem temporariamente.

Conforme Foguel et al (2006) a equação (4) simula o nível educacional permitindo que a distribuição das quantidades varie ao longo do tempo, porém mantendo constantes o vetor de preços e a distribuição dos não observáveis do período s. Em outras

\footnotetext{
${ }^{4} \mathrm{O}$ subscrito it não denota um painel de dados. O termo é usado para caracterizar um agrupamento de dados cross section para diferentes períodos de tempo. Isso se faz necessário, pois a metodologia de JMP é baseada em uma série de dados cross section.

${ }^{5} \mathrm{O}$ termo de erro deve ter média condicional nula, ou seja $E\left[u_{i t} \mid X_{i t}\right]=0$. Forgel et al (2006) afirmam que essa hipótese é muito forte, pois assume a inexistência de correlação entre as covariadas e o termo de erro da regressão.
} 
palavras, ela cria uma distribuição contra factual dos nível de escolaridade caso os preços e os não observáveis fossem os do período $s$, porém com as quantidades observadas em cada $t$.

Da mesma forma, podemos simular a distribuição $y_{i t}$ variando tanto a quantidade como o preço, mantendo constante a distribuição dos não observáveis do período $s$. Neste caso teremos:

$$
y_{i t}^{2}=X_{i t} \beta_{t}+\bar{F}_{S}^{-1}\left(\theta_{i t} \mid X_{i t}\right)
$$

E por fim, permitindo variação de todos os componentes, ou seja, a variação da quantidade, preço e resíduo pode ser descrita como:

$$
y_{i t}^{3}=X_{i t} \beta_{t}+F_{t}^{-1}\left(\theta_{i t} \mid X_{i t}\right)=X_{i t} \beta_{t}+u_{i t}=y_{i t}
$$

que retorna a distribuição observada no período $t$.

A decomposição tem por objetivo calcular a distribuição de $y_{i t}^{1}, y_{i t}^{2}$ e $y_{i t}^{3}$ para cada grupo do presente estudo, ou seja, para jovens que estão no ensino fundamental do estado de São Paulo (referência) e entre jovens que estão no ensino fundamental das demais regiões (avaliado). Será atribuído como desigualdade: mudanças ao longo do tempo em $y_{i t}^{1}$, ou seja, alterações nas quantidades observáveis; qualquer alteração adicional em $y_{i t}^{2}$, isto é, mudança nos parâmetros observáveis e por fim qualquer alteração adicional em $y_{i t}^{3}$, ou seja, uma alteração na distribuição dos resíduos.

Para compreender melhor esse processo, seja $\mathrm{D}($.) uma medida de desigualdade qualquer. Denote $Y_{i t}^{k}=\exp \left(y_{i t}^{k}\right)$, em que $k=1,2$ e 3, então podemos definir a contribuição das quantidades $(k=1)$, dos preços $(k=2)$ e não observáveis $(k=3)$ para a desigualdade total no período $t$, entre o grupo avaliado $i$ e o grupo de referência $s$, respectivamente como:

$$
\begin{gathered}
Q_{t}=D\left(Y_{i t}^{1}\right) \\
P_{t}=D\left(Y_{i t}^{2}\right)-D\left(Y_{i t}^{1}\right) \\
U_{t}=D\left(Y_{i t}^{3}\right)-D\left(Y_{i t}^{2}\right)
\end{gathered}
$$

Perceba que: $Q_{t}+P_{t}+U_{t}=D\left(y_{i t}^{3}\right)=D\left(Y_{i t}\right)=T_{t}$, ou seja, a desigualdade educacional total $\left(T_{t}\right)$, no período $t$ entre o grupo avaliado $i$ e o grupo de referência $s$, pode ser decomposta pelos componentes: mudança nas características (quantidade), mudança de preços (parâmetros) e mudança nos atributos não observáveis (resíduos). Foguel et al (2006) observa que essa metodologia só permite interpretações contra factuais dos efeitos quantidade, preços e não observáveis em um período de tempo $t$ para os diversos grupos em relação ao grupo de referência s. Isso significa que não podemos utilizá-la para calcular a contribuição desses efeitos entre dois outros períodos quaisquer, isto é, entre períodos diferentes do utilizado para o grupo de referência s.

A variável explicada neste estudo será nível de escolaridade. Para avaliar mudanças estruturais na desigualdade educacional entre as regiões, consideraremos o estado de São Paulo (SP) como referência ( $s$ ) e as demais regiões a serem comparados. Para facilitar o entendimento, o método será explicado usando a região Centro Oeste (CO) como 
p. 67 - As características dos indivíduos são determinantes para as desigualdades regionais em educação no Brasil? Uma análise para os anos de 2004 e 2014

comparação (i). A partir da equação (4), ao considerar $t=2004, i=\mathrm{CO}$ e $s=\mathrm{SP}$, podemos escrever o seguinte:

$$
y_{C O, 2004}^{1}=X_{C O, 2004} \bar{\beta}_{S P, 2004}+\bar{F}_{2004}^{-1}\left(\theta_{S P} \mid X_{S P}\right)
$$

A equação (10) cria uma distribuição contra factual do nível de estudo para os jovens da região Centro Oeste (CO) caso os preços e os não observáveis ${ }^{6}$ fossem os resultados do estado de São Paulo (SP), porém com as quantidades observadas ${ }^{7}$ para a região Centro Oeste.

A partir da equação (5) podemos simular a distribuição $y_{i t}$ variando tanto a quantidade como o preço, mantendo constante a distribuição dos não observáveis do nível de escolaridade.

$$
y_{C O, 2004}^{2}=X_{C O, 2004} \beta_{C O, 2004}+\bar{F}_{2004}^{-1}\left(\theta_{S P} \mid X_{S P}\right)
$$

E a partir da equação (6) podemos simular a variação de todos os componentes para o nível educacional e com isso obter a distribuição $y_{C O, 2004}^{3}$.

$$
y_{C O, 2004}^{3}=X_{C O, 2004} \beta_{C O, 2004}+F_{2004}^{-1}\left(\theta_{C O} \mid X_{C O}\right)
$$

Agora podemos definir a contribuição das quantidades $\left(y_{C O, 2004}^{1}\right)$, dos preços $\left(y_{C O, 2004}^{2}\right)$ e não observáveis $\left(y_{C O, 2004}^{3}\right)$ para a desigualdade educacional da região Centro Oeste (CO) no ano de 2004 tendo o estado de São Paulo (SP) como referência, conforme abaixo:

$$
\begin{gathered}
Q_{C O}=D\left(Y_{C O, 2004}^{1}\right) \\
P_{C O}=D\left(Y_{C O, 2004}^{2}\right)-D\left(Y_{C O, 2004}^{1}\right) \\
U_{C O}=D\left(Y_{C O, 2004}^{3}\right)-D\left(Y_{C O, 2004}^{2}\right)
\end{gathered}
$$

Perceba que: $\quad Q_{C O}+P_{C O}+U_{C O}=D\left(Y_{C O, 2004}\right)=D_{T C O, 2004}$ ou seja, $\left(D_{T C O, 2004}\right)$ representa a desigualdade educacional total entre a região Centro Oeste (GO) e São Paulo (SP) para o ano 2004.

$$
D_{T C O, 2004}=Q_{C O}+P_{C O}+U_{C O}
$$

A equação (16) pode ser decomposta pelos componentes: mudança nas características $Q_{C O}$ - (quantidade), mudança de preços - $P_{C O}$ (parâmetros) e mudança nos atributos não observáveis - $U_{C O}$ (resíduos). Os estudos para as demais regiões bem como para o ano de 2014 são análogos à metodologia apresentada.

\footnotetext{
${ }^{6}$ Preços e não observáveis do nível de escolaridade corresponde aos termos: $\bar{\beta}_{i t}$ e $\bar{F}_{t}^{-1}\left(\theta_{i} \mid X_{i}\right)$, respectivamente.

${ }^{7}$ Quantidades Observadas corresponde ao termo: $X_{i t}$
} 


\section{RESULTADOS}

As tabelas 1 e 2 apresentam os resultados da decomposição e está separada da seguinte forma: a primeira coluna mostra as variáveis de controle utilizadas na regressão ; da segunda até a sétima coluna será ilustrado os resultados da decomposição, por região, dos anos de 2004 e 2014 respectivamente, comparando os anos de estudo dos jovens de 14 a 17 do estado de São Paulo (referência) com as demais regiões.

As diferenças regionais nas médias de anos de estudo são elevadas. Em termos absolutos, a desvantagem é maior entre os estados das regiões Norte e Nordeste. Comparadas a São Paulo, estas regiões apresentam uma defasagem média de cerca de 2,05 e 1,99 anos de estudo, respectivamente, como mostra a tabela 1. Este resultado significa dizer que quanto mais distante de zero, maior será a desigualdade educacional das regiões em relação a São Paulo. Também se observam desigualdades nas demais regiões, a região Sudeste apresenta uma diferença em torno de 0,67 anos de estudo em relação à São Paulo. A região Centro Oeste, bem como o Distrito Federal, apresentam uma diferença de 0,80 e 0,56 anos de estudo, respectivamente. A região Sul, é a região em que se observa menor diferença entre o estado de São Paulo, uma diferença de apenas 0,36 anos de estudo. Logo, a região Sudeste é a região que está mais próxima em termos educacionais do estado de São Paulo, enquanto que o Norte é a região mais distante. Diante deste cenário, vamos analisar adiante quais os fatores são determinantes para essa desigualdade, isto é, quais características tem maior contribuição.

Fazendo uma análise comparativa dos resultados apresentados na tabela 1 é possível inferir que as características individuais tem baixa participação dentro da desigualdade total, ou seja, ela representa $28 \%(0.57 / 2.05)$ do total da desigualdade educacional na região Norte, $29 \%$ no Centro Oeste, $24 \%$ no Nordeste, $25 \%$ no Sudeste, $7 \%$ no Distrito Federal e apenas 2\% na região Sul. Os autores Medeiros e Oliveira (2013) alegam que as características individuais são fatores importantes na desigualdade educacional, pois parte dessa desigualdade é observada e pode ser alterada ao longo do tempo. Contudo não é o fator com maior peso para explicar a desigualdade educacional entre as regiões.

Este resultado também é encontrado por Barros e Mendonça (2000). O autor avalia em seu trabalho o desempenho educacional, no Nordeste, tende a ser relativamente mais sensível às características individuais, ao passo que, no Sul e Sudeste, este impacto não é tão representativo, isto é, desempenho educacional dos jovens depende mais fortemente das características familiares na região Nordeste do que no Sul.

\footnotetext{
${ }^{8}$ As regressões que geram os resultados das decomposições encontram-se no Anexo.
} 
p. 69 - As características dos indivíduos são determinantes para as desigualdades regionais em educação no Brasil? Uma análise para os anos de 2004 e 2014

Tabela 1 - Decomposição das desigualdades educacionais entre regiões no ano de 2004.

\begin{tabular}{|c|c|c|c|c|c|c|}
\hline & REGIĨO & & & & & \\
\hline & NO & NE & SU & SE & $\mathrm{CO}$ & DF \\
\hline 1. Características Individuais & \multirow{2}{*}{0.57} & \multirow{2}{*}{0.47} & \multirow{2}{*}{0.008} & \multirow{2}{*}{0.17} & \multirow{2}{*}{0.23} & \multirow{2}{*}{0.04} \\
\hline$X_{i t} \bar{\beta}_{S}+\bar{F}_{S}^{-1}\left(\theta_{i t} \mid X_{i t}\right)$ & & & & & & \\
\hline \multicolumn{7}{|l|}{ Características dos Filhos } \\
\hline 1.1. Gênero Filho = Feminino & 0.002 & 0.008 & 0.00008 & 0.001 & 0.001 & -0.003 \\
\hline 1.2. Raça Filho - Pardo & 0.029 & 0.03 & -0.004 & 0.013 & 0.013 & 0.03 \\
\hline 1.3. Raça Filho - Preto & 0.00001 & -0.0001 & -0.0002 & 0.0003 & -0.0002 & -0.004 \\
\hline 1.4. Escola Particular & $0.013 \Delta$ & $0.018 \triangle$ & $0.010 \triangle$ & $0.007 \Delta$ & $0.005 \Delta$ & -0.01 \\
\hline \multicolumn{7}{|l|}{ Características da Mãe } \\
\hline 1.5. Educação Mãe - 1-3 anos de estudo & $-0.007 \nabla$ & $-0.005 \nabla$ & $0.001 \nabla$ & $0.004 \nabla$ & $0.002 \nabla$ & 0.002 \\
\hline 1.6. Educação Mãe - 4-7 anos de estudo & 0.027 & $-0.003 \nabla$ & $0.036 \nabla$ & $0.025 \nabla$ & $0.016 \nabla$ & 0.020 \\
\hline 1.7. Educação Mãe - 8-10 anos de estudo & 0.054 & 0.032 & $0.005 \nabla$ & 0.025 & 0.014 & 0.048 \\
\hline 1.8. Educação Mãe - 11-14 anos de estudo & 0.14 & 0.10 & 0.063 & 0.076 & 0.051 & $-0.031 \nabla$ \\
\hline 1.9. Educação Mãe - 15 ou + anos de estudo & 0.06 & 0.06 & 0.015 & 0.020 & 0.024 & $-0.050 \nabla$ \\
\hline 1.10. Raça Mãe - Branca & $0.31 \Delta$ & $0.34 \Delta$ & -0.016 & $0.17 \Delta$ & $0.21 \Delta$ & $0.08 \Delta$ \\
\hline 1.11. Raça Mãe - Parda & -0.40 & -0.44 & -0.002 & -0.21 & -0.27 & -0.07 \\
\hline 1.12. Raça Mãe - Preta & -0.006 & 0.005 & 0.013 & -0.02 & 0.002 & 0.007 \\
\hline 1.13. Idade Mãe & 0.15 & 0.10 & 0.042 & 0.09 & -0.05 & -0.01 \\
\hline 1.14. Horas Trabalhadas - Mãe & -0.01 & -0.01 & -0.006 & -0.005 & -0.005 & 0.0002 \\
\hline \multicolumn{7}{|l|}{ Características do Pai } \\
\hline 1.15. Educação Pai - 1-3 anos de estudo & $-0.08 \nabla$ & $-0.08 \nabla$ & 0.018 & $-0.08 \nabla$ & 0.08 & 0.0017 \\
\hline 1.16. Educação Pai - 4-7 anos de estudo & 0.08 & 0.04 & 0.041 & 0.012 & -0.070 & 0.014 \\
\hline 1.17. Educação Pai - 8-10 anos de estudo & 0.06 & 0.04 & 0.0008 & 0.027 & 0.012 & 0.009 \\
\hline 1.18. Educação Pai - 11-14 anos de estudo & 0.13 & 0.11 & $-0.04 \nabla$ & 0.079 & 0.033 & $-0.009 \nabla$ \\
\hline 1.19. Educação Pai - 15 ou + anos de estudo & 0.048 & 0.04 & $0.012 \nabla$ & 0.017 & 0.054 & $-0.013 \nabla$ \\
\hline 1.20. Raça Pai - Branco & $0.045 \Delta$ & $0.05 \Delta$ & -0.004 & $0.028 \Delta$ & $0.027 \Delta$ & $0.011 \Delta$ \\
\hline 1.21. Raça Pai - Pardo & 0.13 & 0.15 & -0.010 & 0.069 & 0.08 & -0.001 \\
\hline 1.22. Raça Pai - Preto & 0.005 & 0.006 & -0.007 & 0.021 & 0.00084 & -0.0002 \\
\hline 1.23. Idade Pai & -0.24 & -0.16 & -0.016 & -0.14 & 0.08 & 0.015 \\
\hline \multicolumn{7}{|l|}{ Características Familiares } \\
\hline 1.24. Renda & $0.009 \Delta$ & $0.006 \Delta$ & $0.001 \Delta$ & $0.003 \Delta$ & $0.004 \mathbf{A}$ & $0.001 \Delta$ \\
\hline 1.25. Rural & - & - & - & - & - & - \\
\hline $\begin{array}{l}\text { 2. Diferença nas respostas (parâmetros) } \\
\qquad \boldsymbol{X}_{i t} \boldsymbol{\beta}_{t}+\overline{\boldsymbol{F}}_{S}^{-1}\left(\boldsymbol{\theta}_{i t} \mid \boldsymbol{X}_{i t}\right)\end{array}$ & 1.48 & 1.51 & 0.34 & 0.49 & 0.55 & 0.50 \\
\hline $\begin{array}{l}\text { 3. Diferença em não observados (resíduos) } \\
\qquad \boldsymbol{X}_{i t} \boldsymbol{\beta}_{t}+\boldsymbol{F}_{t}^{-1}\left(\boldsymbol{\theta}_{i t} \mid \boldsymbol{X}_{i t}\right) \\
\end{array}$ & 0.001 & 0.003 & 0.004 & 0.004 & 0.007 & 0.007 \\
\hline $\begin{array}{l}\text { 4. Desigualdade Educacional Total } \\
(1+2+3)\end{array}$ & 2.05 & 1.99 & 0.36 & 0.67 & 0.80 & 0.56 \\
\hline
\end{tabular}

Fonte: Criado pela autora, a partir dos dados da PNAD 2004.

$\boldsymbol{\Delta}$ - As setas vermelhas indicam que as variáveis contribuem para aumentar o diferencial entre os grupos.

$\nabla$ - As setas azuis indicam que as variáveis contribuem para reduzir o diferencial entre os grupos. 
O resultado negativo das características individuais mostra que elas são favoráveis à queda da desigualdade educacional. Isso quer dizer que se houver uma melhoria nas variáveis de controle ao longo do tempo, elas contribuirão para reduzir o gap educacional entre as regiões. Analisando os valores negativos encontrados nas variáveis de educação da mãe, por exemplo, é possível inferir que caso haja um aumento do nível de escolaridade das mães, o resultado negativo indica que haverá uma redução do gap educacional das regiões, quando comparado ao estado de referência, São Paulo. Portanto, o nível de escolaridade dos pais impacta positivamente no desempenho escolar dos filhos (BARROS et al. 2001).

Se os valores negativos apresentam impacto positivo para redução da desigualdade educacional entre as regiões, os valores positivos contribuem para aumentar essa diferença. A renda per capita das famílias, por exemplo, é um fator que colabora para a desigualdade educacional entre as regiões. Filhos de pais pobres, por exemplo, tendem a ter menos educação que filhos de pais ricos. Por este motivo, regiões com maior proporção de pobres tendem a ter médias educacionais mais baixas que as demais. Fato que pode ser observado na tabela 1, em que a média educacional das regiões Norte e Nordeste são menores que as demais regiões do país.

No entanto, os resultados obtidos neste estudo sugerem que não é a desigualdade na distribuição das características dos indivíduos e das famílias, o maior responsável pela desigualdade regional educacional, e sim a desigualdade na resposta a essas características. Isto é, o efeito maior é o da desigualdade nas respostas a essas características, que são medidas pelos parâmetros das regressões. Esse efeito responde por $72 \%$ (1.48/2.05) da defasagem na região Norte, $76 \%$ da defasagem do Nordeste, $73 \%$ nos estados do Sudeste, $69 \%$ nos estados do Centro Oeste, e praticamente toda a defasagem do Sul, representando $94 \%$ da diferença regional em educação.

Em outras palavras, a maioria da desigualdade regional em educação não é determinada por distinções nas características das populações de cada região e sim pela forma diferenciada como essas características afetam a educação. Por exemplo, se houver um aumento no nível educacional dos pais, os retornos gerados por esse aumento trará maior benefício aos jovens das regiões analisadas, do que para os jovens do estado de São Paulo, reduzindo, portanto, o gap entre eles.

Segundo Medeiros e Oliveira (2013) para influenciar o nível educacional dos jovens, suas características individuais e familiares precisam ser transformadas ou convertidas em educação pela ação de algum mecanismo social, uma vez que a desigualdade regional está mais associada à força desse tipo de mecanismo do que a diferenças características das populações.

Finalmente, o efeito na diferença nos resíduos apresenta um resultado positivo, sugerindo, em média, que contribuem para reduzir a desigualdade. No entanto, seus valores são extremamente baixos, permitindo concluir, com certa cautela, que características não observadas não aparecem como explicação relevante para as desigualdades regionais nas decomposições realizadas. Ou seja, não é possível afirmar com total segurança que alguma característica não observada neste estudo tem relevância para explicar a desigualdade regional no ano de 2004. 
p. 71 - As características dos indivíduos são determinantes para as desigualdades regionais em educação no Brasil? Uma análise para os anos de 2004 e 2014

Analisando os resultados de 2014, expostos na tabela 2, verifica-se que diferenças regionais nas médias de anos de estudo são elevadas, em termos absolutos, nas regiões Norte e Nordeste. No entanto houve redução, se comparado a 2004. Para a região Norte a queda foi de $44 \%$ na desigualdade educacional total, já na região Nordeste a queda foi de $36 \%$, no Sul e Centro Oeste a queda foi 33\% enquanto que no Sudeste e no Distrito Federal foi de $4 \%$.

Os estados das regiões Norte e Nordeste, comparadas a São Paulo, apresentam uma defasagem média de cerca de 1,14 e 1,27 anos de estudo, respectivamente, já os estados da região Sudeste apresentam uma defasagem em torno de 0,64 anos de estudo. Os estados da região Centro Oeste, bem como o Distrito Federal apresenta uma diferença de 0,54 anos de estudo. A região Sul, novamente é a região em que se observa menor diferença entre o estado de São Paulo, uma desvantagem de apenas 0,27 anos de estudo.

A queda na desigualdade educacional entre as regiões pode ser explicada tanto pela redução na distribuição das características dos indivíduos e das famílias como pela queda nas respostas a essas características. Para a região Norte a queda na distribuição das características entre o ano de 2004 e 2014 foi de 37\%, na região Nordeste a queda foi $47 \%$, no Sudeste $41 \%$ e no Centro Oeste foi de $56 \%$. Diante deste cenário é possível verificar que uma melhoria na distribuição dessas características é fator preponderante para a redução da desigualdade educacional regional. Parte dessa melhoria pode ser explicada pela melhora no nível educacional de todas as regiões, conforme já apresentado na tabela 1. Pais com nível educacional mais elevado (entre 11 e 14 anos de estudo; e mais de 15 anos de estudo) apresentaram valores negativos em 2014, contribuindo, portanto para redução da desigualdade educacional.

A melhoria na distribuição das características foi mais expressiva nas regiões Sul e no Distrito Federal. Nos dois casos, verifica-se que as características individuais apresentam valores negativos, impactando assim, positivamente para redução da desigualdade educacional. Além do nível educacional dos pais, o fato de os filhos estudarem em escola particular bem como a mãe trabalhar 15 horas ou mais contribuíram para a queda da desigualdade educacional das regiões.

Um ponto importante a ser observado é o fato de jovens estudarem em escola particular contribuir para a redução da desigualdade. Este resultado permite inferir que caso haja um aumento do número de jovens estudando em escolas particulares, o resultado negativo indica que haverá uma redução do gap educacional das regiões, quando comparado ao estado de referência, São Paulo. De outro ponto de vista, o fato de os jovens estudarem em escolas públicas (Municipais ou Federais) nas regiões analisadas, aumenta o gap educacional entre o estado de São Paulo. Há, evidentemente, vários fatores influenciando a conversão de atributos pessoais e familiares em educação, e a escola é apenas um deles; todavia, os resultados indicam que é provável que uma convergência regional na qualidade das escolas tenha um impacto importante na desigualdade entre regiões. Logo, para que haja uma redução neste gap é necessário que as escolas públicas passem a ter o mesmo desempenho das escolas particulares. A partir dessa constatação é possível mostrar os pontos que políticas públicas podem atuar para reduzir a desigualdade educacional entre os estados. 
Tabela 2 - Decomposição das desigualdades educacionais entre regiões no ano de 2014.

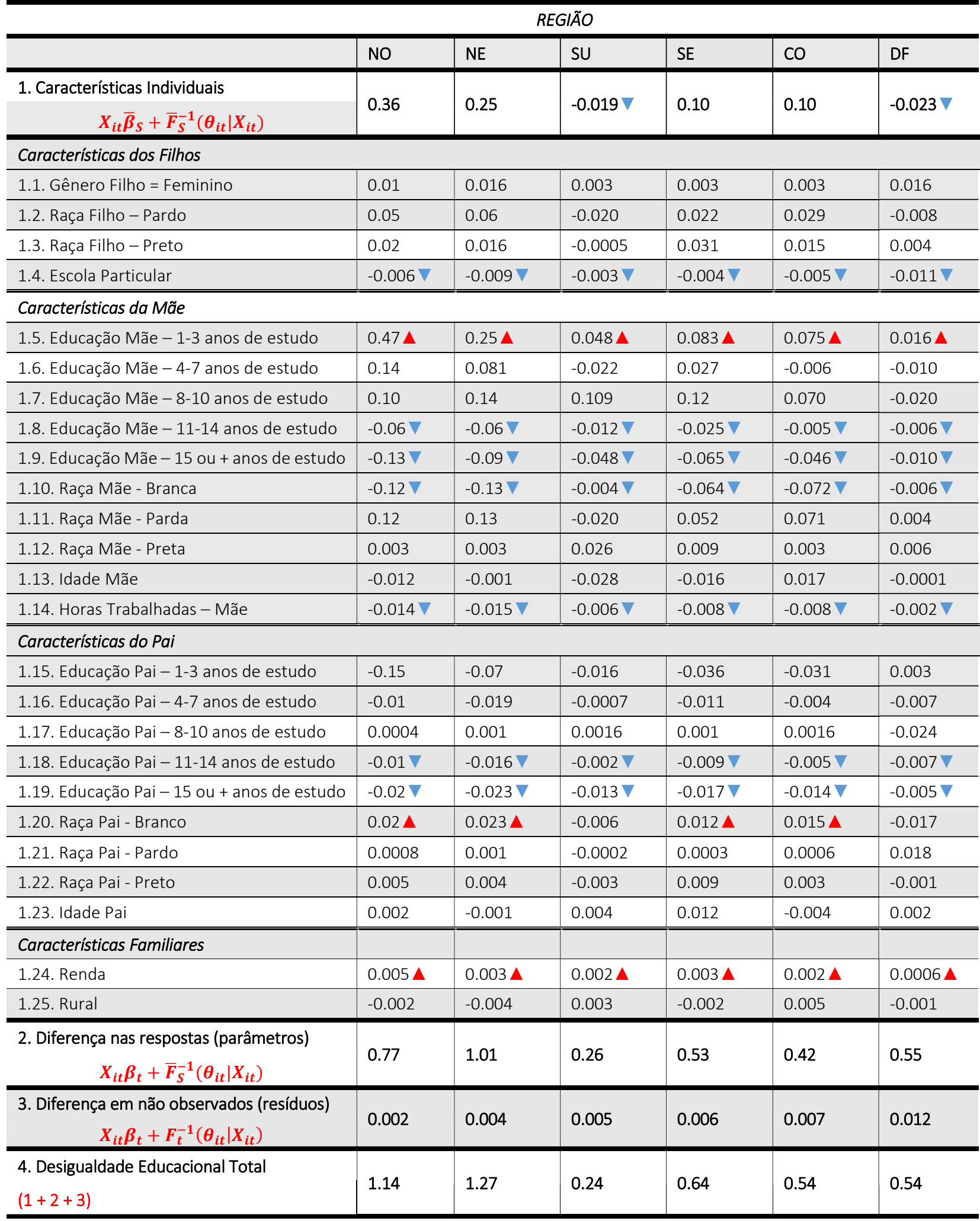

Fonte: Criado pela autora, a partir dos dados da PNAD 2014.

$\boldsymbol{\Delta}$ - As setas vermelhas indicam que as variáveis contribuem para aumentar o diferencial entre os grupos.

$\nabla$ - As setas azuis indicam que as variáveis contribuem para reduzir o diferencial entre os grupos. 
p. 73 - As características dos indivíduos são determinantes para as desigualdades regionais em educação no Brasil? Uma análise para os anos de 2004 e 2014

Contudo, assim como constatado no ano de 2004, as características individuais não são os principais fatores para contribuir com a desigualdade educacional regional, a respostas a essas características no ano de 2014 também representa maior peso nessa desigualdade. No entanto, é importante observar que houve uma queda desses parâmetros em 2014. Na região Norte a queda foi de 47\%, na região Nordeste foi de 33\%, já nas regiões Sul e Centro Oeste a queda foi de $23 \%$. Como maior parte da desigualdade é explicada pela forma diferenciada como essas características afetam a educação, então pode-se inferir que, os retornos gerados pelo o aumento no nível educacional dos pais gerou maior benefício aos jovens das regiões analisadas, reduzindo, assim, o gap educacional.

A partir disso é possível afirmar que para haver uma queda expressiva na desigualdade educacional, a ação deve ser tomada a partir de algum mecanismo social, uma vez que a desigualdade regional está mais associada à força desse tipo de mecanismo do que a diferenças características das populações. Logo, não basta apenas investir na melhoria das características individuais como atributos educacionais ou mesmo melhorar o desempenho das escolas públicas, é necessário gerar políticas públicas capazes de neutralizar o peso da origem social.

Por fim, o efeito na diferença nos resíduos, assim como em 2004, são extremamente baixo, e com isso, é possível concluir que características não observadas não são relevantes para explicar as desigualdades regionais nas decomposições realizadas.

\section{CONCLUSÃO}

O presente trabalho tenta identificar, a partir do método de decomposição proposto por Juhn, Murphy e Pierce (1993), se a distribuição espacial de características dos indivíduos e seus familiares, que reconhecidamente afetam a educação das crianças e jovens, são determinantes importantes das elevadas desigualdades regionais em educação que são observadas no Brasil, para os anos de 2004 e 2014.

Com os resultados expostos anteriormente, é possível concluir que a educação dos pais é um determinante importante para a desigualdade regional em educação. Outra variável que apresentou resultado determinante na desigualdade foi o fato de os jovens estudarem em escolas particulares, permitindo com isso, inferir que o fato dos jovens estudarem em escolas públicas aumenta a desigualdade. Este resultado mostra a necessidade das políticas públicas atuarem na qualidade do ensino nas escolas públicas para reduzir a desigualdade educacional entre os estados.

Além das características individuais, a respostas a essas características (diferença nas respostas) também são determinantes da desigualdade. Para ser mais específica, a resposta dos parâmetros é o principal responsável pela elevada defasagem educacional entre os estados. A diferença nas respostas às características mostra que se houver um aumento no nível educacional dos pais, os retornos gerados por esse aumento trará maior benefício aos jovens das regiões analisadas, do que para os jovens do estado de São Paulo, reduzindo, portanto, o gap entre eles. 
Este mesmo resultado foi encontrado no trabalho de Medeiros e Oliveira (2013). Os autores concluem que para influenciar o nível educacional dos jovens, tanto suas características individuais como as de seus familiares precisam ser transformadas ou convertidas em educação pela ação de algum mecanismo social. Com isso, investir na melhoria das características individuais como atributos educacionais ou mesmo melhorar o desempenho das escolas públicas não é suficiente para reduzir a desigualdade educacional, é necessário gerar políticas públicas capazes de neutralizar o peso da origem social, para que as respostas a essas características contribuam efetivamente com na queda da desigualdade educacional regional.

\section{REFERÊNCIA BIBLIOGRÁFICA}

ALVES, M. T. G.; SOARES, J. F. As pesquisas sobre o efeito das escolas: contribuições metodológicas para a sociologia da educação. Sociedade e Estado, Brasília, v. 22, n. 2, p. 435-473, 2007.

AMADEO, E., CAMARGO, J. M., GONZAGA, G., BARROS, R., \& MENDONÇA, R. A natureza e o funcionamento do mercado de trabalho brasileiro desde 1980. Texto para Discussão: IPEA, Rio de Janeiro, n.353, 1995.

BARROS, R. P. D., MENDONÇA, R., Santos. Uma análise dos determinantes do desempenho educacional no Brasil. Projeto Nordeste, Brasília, Serie de Estudo n. 8, 2000.

BARROS, R. P. D., MENDONÇA, R., SANTOS, D. D. D., \& QUINTAES, G. Determinantes do desempenho educacional no Brasil. Pesquisa e planejamento econômico, Rio de Janeiro, v. 31, n. 1, p. 1-42, 2001.

BARROS, Ricardo e LAM, David. (1993), "Income Inequality, Inequality in Education, and Children's Schooling Attainment in Brazil”. Textos para Discussão № 294, IPEA.

BELTRÃO, K. I.; CAMARANO, A. A.; KANSO, S. Ensino fundamental: diferenças regionais. Revista brasileira de estudos de população, v. 19, n. 2, p. 135-157, 2002.

BEHRMAN, J. R. Is child schooling a poor proxy for child quality? From parent to child: intrahousehold allocations and intergenerational relations in the United States. Chicago: Chicago University Press, p. 183-206, 1995.

BLINDER, Alan S. Wage discrimination: reduced form and structural estimates. Journal of Human resources, p. 436-455, 1973.

CASTRO, M. H. G. As desigualdades regionais no sistema educacional brasileiro. In: HENRIQUES, R. (Org.). Desigualdade e pobreza no Brasil. Rio de Janeiro: Ipea, 2000. p. 425-458.

CESAR, C. C.; SOARES, J. F. Desigualdades acadêmicas induzidas pelo contexto escolar. Revista brasileira de estudos de população, v. 18, n. 1-2, p. 97-110, 2001.

COLEMAN, James S. et al. Equality of educational opportunity. National center for educational statistics 1966.

CRESPO, Anna Risi Vianna; FERREIRA, Francisco H. G. Desigualdade entre Raças e Gêneros: uma análise com simulações contra-factuais. Dissertação de Mestrado - 
p. 75 - As características dos indivíduos são determinantes para as desigualdades regionais em educação no Brasil? Uma análise para os anos de 2004 e 2014

Departamento de Economia, Pontifícia Universidade Católica do Rio de Janeiro. Rio de Janeiro. 2003. 83

DE CASTRO, Jorge Abrahão. Evolução e desigualdade na educação brasileira. Educação \& Sociedade, v. 30, n. 108, 2009.

FOGUEL, M. N. \& AZEVEDO, J. P. Uma Decomposição da Desigualdade de Rendimentos do Trabalho no Brasil: 1984-2005, Texto de Discussão 1247, Instituto de Pesquisa Econômica Aplicada - IPEA, 2006.

GONÇALVES, F. de O.; FRANÇA, M. T. A. Transmissão intergeracional de desigualdade e qualidade educacional: avaliando o sistema educacional brasileiro a partir do SAEB 2003. Ensaio: avaliação e políticas públicas em educação, v. 16, n. 61, p. 639-662, 2008.

JUHN, C., MURPHY, K. M. and PIERCE, B.; Wage inequality and the rise in returns to skill. Journal of Political Economy, 101(3):410 - 442, 1993.

LAM, David; MARTELETO, Letícia. A escolaridade das crianças brasileiras durante a transição demográfica: aumento no tamanho da coorte versus diminuição no tamanho da família. Pesquisa e Planejamento Econômico, IPEA V. 36, n. 2, 2006.

MACHADO, Danielle Carusi; GONZAGA, Gustavo. O impacto dos fatores familiares sobre a defasagem idade-série de crianças no Brasil. Revista Brasileira de Economia, v. 61, n. 4, p. 449-476, 2007.

MEDEIROS, Marcelo; OLIVEIRA, Luis Felipe Batista de.; Potencial de convergência regional em educação no Brasil. Texto de Discussão 1888, Instituto de Pesquisa Econômica Aplicada - IPEA, 2013.

MONSUETO, Sandro Eduardo. Distribuição de renda no Brasil: a situação dos $25 \%$ mais pobres. Dissertação apresentada ao curso de mestrado do Centro de Desenvolvimento e Planejamento Regional da Faculdade de Ciências Econômicas da Universidade Federal de Minas Gerais, 2003.

OAXACA, Ronald. Male-female wage differentials in urban labor markets. International economic review, p. 693-709, 1973.

PLANK, David N. (1996), The Means of Our Salvation, Public Education in Brazil, 19301995. Boulder, Co., Westview Press.

PISA 2015 : Análises e reflexões sobre o desempenho dos estudantes brasileiros / OCDEOrganização para a Cooperação e Desenvolvimento Econômico. - São Paulo : Fundação Santillana, 2016

RIGOTTI, I. A transição da escolaridade no Brasil e as desigualdades regionais. Revista brasileira de estudos de população, v. 18, n. 1-2, p. 59-73, 2001.

SILVA, N. do V.; HASENBALG, C. Tendências da desigualdade educacional no Brasil. Dados, v. 43, n. 3, p. 423-445, 2000.

SCHWARTZMAN, L. F.; Does Money Whiten? Intergenerational Changes in Racial Classification in Brazil. American Sociological Review, VOL. 72 (December: 940-963), 2007. 
ANEXOS

Tabela A 1 - Resultados da regressão usada na Decomposição no ano de 2004

\begin{tabular}{|c|c|c|c|c|c|c|c|}
\hline & eduF (SP) & eduF (NO) & eduF (NE) & eduF (CO) & eduF (SU) & eduF (SE) & eduF (DF) \\
\hline \multirow[t]{2}{*}{ racaF=3 } & -0.061 & -0.015 & -0.068 & 0.060 & $-0.300 * * *$ & -0.197 & 0.077 \\
\hline & $(0.22)$ & $(0.10)$ & $(0.16)$ & $(0.23)$ & $(0.17)$ & $(0.14)$ & (0.18) \\
\hline \multirow[t]{2}{*}{ racaF=4 } & -0.014 & 0.166 & $0.791^{* * *}$ & 0.180 & $-0.863 * * *$ & -0.278 & -0.109 \\
\hline & $(0.51)$ & $(0.27)$ & $(0.44)$ & $(0.58)$ & $(0.47)$ & $(0.38)$ & $(0.36)$ \\
\hline \multirow[t]{2}{*}{ generoF=4 } & $0.182 * * *$ & $0.758^{*}$ & $0.800^{*}$ & $0.483^{*}$ & $0.768 *$ & $0.453^{*}$ & $0.639 *$ \\
\hline & $(0.10)$ & $(0.07)$ & $(0.11)$ & $(0.09)$ & $(0.13)$ & $(0.10)$ & $(0.13)$ \\
\hline \multirow[t]{2}{*}{ Particular } & 0.216 & $0.743^{*}$ & $0.751^{*}$ & $0.813^{*}$ & $0.760 *$ & 0.029 & $0.504^{* *}$ \\
\hline & $(0.16)$ & $(0.16)$ & $(0.25)$ & $(0.18)$ & $(0.23)$ & $(0.20)$ & $(0.23)$ \\
\hline \multirow[t]{2}{*}{ Inrend } & 0.011 & 0.011 & 0.013 & $0.055^{* *}$ & 0.111 & $0.034 * *$ & 0.032 \\
\hline & $(0.03)$ & $(0.01)$ & $(0.02)$ & $(0.02)$ & $(0.07)$ & $(0.02)$ & $(0.02)$ \\
\hline \multirow[t]{2}{*}{ edumae=2 } & 0.048 & $0.274^{* *}$ & $1.042 *$ & -0.394 & 0.403 & 0.544 & 0.470 \\
\hline & $(0.49)$ & $(0.13)$ & $(0.24)$ & $(0.48)$ & $(0.42)$ & $(0.36)$ & $(0.51)$ \\
\hline \multirow[t]{2}{*}{ edumae=3 } & 0.670 & $0.955^{*}$ & $1.476^{*}$ & 0.171 & $1.070 *$ & $1.047^{*}$ & 0.430 \\
\hline & $(0.46)$ & $(0.13)$ & $(0.25)$ & $(0.45)$ & (0.39) & $(0.34)$ & $(0.45)$ \\
\hline \multirow[t]{2}{*}{ edumae=4 } & 0.651 & $1.326 *$ & $2.399 *$ & 0.296 & $1.513^{*}$ & $1.315^{*}$ & $0.987^{* *}$ \\
\hline & $(0.50)$ & $(0.19)$ & $(0.30)$ & $(0.47)$ & $(0.43)$ & $(0.38)$ & $(0.48)$ \\
\hline \multirow[t]{2}{*}{ edumae=5 } & $0.940 * * *$ & $2.059 *$ & $3.093^{*}$ & 0.663 & $1.820 *$ & $1.692 *$ & $1.357^{*}$ \\
\hline & $(0.50)$ & (0.19) & $(0.31)$ & $(0.48)$ & $(0.46)$ & $(0.39)$ & $(0.44)$ \\
\hline \multirow[t]{2}{*}{ edumae=6 } & $0.941^{* * *}$ & $2.214^{*}$ & $3.571^{*}$ & 0.770 & 0.874 & 1.997* & 0.916 \\
\hline & $(0.55)$ & $(0.28)$ & $(0.37)$ & $(0.52)$ & $(0.60)$ & $(0.46)$ & (0.59) \\
\hline \multirow[t]{2}{*}{ edupai=2 } & $0.760 * *$ & $0.205^{* * *}$ & -0.230 & $1.007^{*}$ & 0.076 & 0.141 & 0.399 \\
\hline & $(0.36)$ & $(0.12)$ & $(0.20)$ & $(0.31)$ & $(0.29)$ & $(0.27)$ & $(0.41)$ \\
\hline \multirow[t]{2}{*}{ edupai=3 } & $0.609 * * *$ & 0.171 & 0.202 & $0.975^{*}$ & 0.185 & 0.259 & 0.194 \\
\hline & $(0.33)$ & $(0.12)$ & $(0.22)$ & $(0.29)$ & $(0.28)$ & $(0.26)$ & $(0.35)$ \\
\hline \multirow[t]{2}{*}{ edupai=4 } & $0.825 * *$ & $0.514^{*}$ & 0.038 & $1.242^{*}$ & 0.042 & 0.367 & 0.243 \\
\hline & $(0.36)$ & $(0.20)$ & $(0.27)$ & $(0.33)$ & $(0.34)$ & $(0.32)$ & $(0.38)$ \\
\hline \multirow[t]{2}{*}{ edupai=5 } & $0.855^{* *}$ & 0.104 & $-0.612^{* * *}$ & $1.061^{*}$ & -0.080 & 0.209 & 0.244 \\
\hline & $(0.38)$ & $(0.20)$ & $(0.32)$ & $(0.34)$ & $(0.38)$ & (0.33) & $(0.35)$ \\
\hline \multirow[t]{2}{*}{ edupai=6 } & $0.852^{* * *}$ & 0.331 & 0.165 & $0.945^{* *}$ & 0.051 & 0.196 & 0.413 \\
\hline & $(0.45)$ & $(0.40)$ & $(0.43)$ & $(0.43)$ & $(0.66)$ & $(0.42)$ & $(0.50)$ \\
\hline \multirow[t]{2}{*}{ idademae } & -0.057 & 0.000 & 0.000 & -0.079 & 0.018 & -0.041 & 0.030 \\
\hline & $(0.05)$ & $(0.03)$ & $(0.02)$ & $(0.06)$ & $(0.04)$ & $(0.03)$ & $(0.05)$ \\
\hline \multirow[t]{2}{*}{ idadepai } & $0.087^{* * *}$ & 0.010 & 0.022 & $0.105^{* * *}$ & 0.005 & 0.054 & -0.017 \\
\hline & $(0.05)$ & $(0.03)$ & $(0.02)$ & $(0.06)$ & $(0.04)$ & $(0.03)$ & $(0.05)$ \\
\hline racapai=2 & 0.103 & 0.013 & -0.283 & 0.178 & -0.329 & $0.370 * *$ & 0.056 \\
\hline & $(0.16)$ & $(0.12)$ & $(0.20)$ & $(0.16)$ & $(0.23)$ & $(0.16)$ & $(0.20)$ \\
\hline racapai=3 & -0.332 & -0.139 & $-0.676^{*}$ & 0.109 & -0.150 & 0.245 & -0.035 \\
\hline & $(0.21)$ & $(0.11)$ & $(0.16)$ & $(0.21)$ & $(0.23)$ & (0.15) & $(0.18)$ \\
\hline racapai=4 & -0.549 & -0.198 & $-0.663 * *$ & -0.408 & -0.034 & 0.316 & -0.011 \\
\hline & $(0.34)$ & $(0.18)$ & $(0.27)$ & $(0.47)$ & $(0.41)$ & $(0.28)$ & $(0.32)$ \\
\hline racamae=2 & 0.605 & 0.566 & 0.213 & 0.645 & 0.306 & 0.267 & 0.155 \\
\hline & $(0.42)$ & $(0.41)$ & $(0.42)$ & $(0.44)$ & $(0.34)$ & $(0.47)$ & $(0.44)$ \\
\hline racamae=3 & $0.772 * * *$ & 0.431 & -0.140 & 0.345 & 0.264 & 0.371 & -0.199 \\
\hline & $(0.45)$ & $(0.41)$ & $(0.41)$ & $(0.47)$ & $(0.33)$ & $(0.48)$ & $(0.44)$ \\
\hline racamae=4 & 0.726 & 0.035 & -0.738 & 0.158 & 0.182 & -0.344 & -0.515 \\
\hline & $(0.57)$ & $(0.45)$ & $(0.58)$ & $(0.63)$ & $(0.47)$ & $(0.53)$ & $(0.50)$ \\
\hline H_Trab_Mae & 0.286 & 0.365 & -0.797 & -0.135 & 0.437 & -0.089 & 0.904 \\
\hline & $(0.48)$ & $(0.26)$ & $(0.49)$ & $(0.35)$ & $(0.54)$ & $(0.43)$ & $(0.64)$ \\
\hline rural & 0.000 & 0.431 & 0.000 & 0.161 & $0.864 * * *$ & -0.595 & -0.541 \\
\hline & (.) & $(0.43)$ & (.) & $(0.24)$ & $(0.48)$ & $(0.56)$ & $(0.38)$ \\
\hline Constant & $5.235^{*}$ & $4.457^{*}$ & $4.435^{*}$ & $4.663^{*}$ & $4.771^{*}$ & $5.324^{*}$ & $5.946^{*}$ \\
\hline & $(0.65)$ & $(0.47)$ & $(0.56)$ & $(0.62)$ & $(0.69)$ & $(0.60)$ & $(0.68)$ \\
\hline R2 Ajustado & 0.0995 & 0.1836 & 0.2318 & 0.1322 & 0.1327 & 0.1258 & 0.1444 \\
\hline № de Obs. & 915 & 3762 & 1445 & 1434 & 899 & 1429 & 670 \\
\hline $\mathrm{F}$ & 5.59 & 35.77 & 24.97 & 8.79 & 7.21 & 9.45 & 5.79 \\
\hline Prob $>F$ & 0.00 & 0.00 & 0.00 & 0.00 & 0.00 & 0.00 & 0.00 \\
\hline
\end{tabular}


p. 77 - As características dos indivíduos são determinantes para as desigualdades regionais em educação no Brasil? Uma análise para os anos de 2004 e 2014

Tabela A 2 - Resultados da regressão usada na Decomposição no ano de 2014

\begin{tabular}{|c|c|c|c|c|c|c|c|}
\hline & eduF (SP) & eduF (NO) & eduF (NE) & eduF (CO) & eduF (SU) & eduF (SE) & eduF (DF) \\
\hline $\mathrm{racaF}=3$ & $\begin{array}{l}-0.160 \\
(0.17)\end{array}$ & $\begin{array}{l}-0.139 \\
(0.10)\end{array}$ & $\begin{array}{l}0.098 \\
(0.16)\end{array}$ & $\begin{array}{l}0.102 \\
(0.17)\end{array}$ & $\begin{array}{l}-0.022 \\
(0.18)\end{array}$ & $\begin{array}{l}-0.263^{* * *} \\
(0.15)\end{array}$ & $\begin{array}{l}0.052 \\
(0.19)\end{array}$ \\
\hline $\mathrm{racaF}=4$ & $\begin{array}{l}-0.567 \\
(0.47)\end{array}$ & $\begin{array}{l}0.208 \\
(0.19)\end{array}$ & $\begin{array}{l}-0.101 \\
(0.28)\end{array}$ & $\begin{array}{l}-0.286 \\
(0.45)\end{array}$ & $\begin{array}{l}0.183 \\
(0.32)\end{array}$ & $\begin{array}{l}-0.062 \\
(0.26)\end{array}$ & $\begin{array}{l}-0.004 \\
(0.36)\end{array}$ \\
\hline generoF=4 & $\begin{array}{l}0.287^{* *} \\
(0.13)\end{array}$ & $\begin{array}{l}0.947^{*} \\
(0.07)\end{array}$ & $\begin{array}{l}0.551^{*} \\
(0.11)\end{array}$ & $\begin{array}{l}0.474^{*} \\
(0.10)\end{array}$ & $\begin{array}{l}0.426^{*} \\
(0.14)\end{array}$ & $\begin{array}{l}0.357^{*} \\
(0.11)\end{array}$ & $\begin{array}{l}0.324^{* *} \\
(0.14)\end{array}$ \\
\hline Particular & $\begin{array}{l}-0.092^{*} \\
(0.20)\end{array}$ & $\begin{array}{l}0.388^{* *} \\
(0.18)\end{array}$ & $\begin{array}{l}1.091^{*} \\
(0.30)\end{array}$ & $\begin{array}{l}1.083^{*} \\
(0.20)\end{array}$ & $\begin{array}{l}0.858^{*} \\
(0.31)\end{array}$ & $\begin{array}{l}0.411^{* * *} \\
(0.23)\end{array}$ & $\begin{array}{l}0.339 * * * \\
(0.20)\end{array}$ \\
\hline Inrend & $\begin{array}{l}0.004^{*} \\
(0.01)\end{array}$ & $\begin{array}{l}0.001^{*} \\
(0.01)\end{array}$ & $\begin{array}{l}0.025^{* *} \\
(0.01)\end{array}$ & $\begin{array}{l}0.002 \\
(0.02)\end{array}$ & $\begin{array}{l}0.001^{*} \\
(0.03)\end{array}$ & $\begin{array}{l}-0.007^{*} \\
(0.02)\end{array}$ & $\begin{array}{l}0.020^{*} \\
(0.02)\end{array}$ \\
\hline edumae=1 & $\begin{array}{l}-3.574^{*} \\
(1.23)\end{array}$ & $\begin{array}{l}-0.491 \\
(0.87)\end{array}$ & $\begin{array}{l}0.890 \\
(1.13)\end{array}$ & $\begin{array}{l}0.620 \\
(1.29)\end{array}$ & $\begin{array}{l}-3.255^{*} \\
(0.78)\end{array}$ & $\begin{array}{l}0.642 \\
(1.11)\end{array}$ & $\begin{array}{l}0.240 \\
(1.36)\end{array}$ \\
\hline edumae $=2$ & $\begin{array}{l}-1.683^{* * *} \\
(0.88)\end{array}$ & $\begin{array}{l}-0.344^{*} \\
(0.88)\end{array}$ & $\begin{array}{l}0.631 \\
(1.11)\end{array}$ & $\begin{array}{l}1.351 \\
(1.18)\end{array}$ & $\begin{array}{l}-2.779 * \\
(0.77)\end{array}$ & $\begin{array}{l}0.520 \\
(1.05)\end{array}$ & $\begin{array}{l}-0.912 \\
(1.30)\end{array}$ \\
\hline edumae $=3$ & $\begin{array}{l}-1.157 \\
(0.82)\end{array}$ & $\begin{array}{l}0.075 \\
(0.87)\end{array}$ & $\begin{array}{l}1.229^{*} \\
(1.11)\end{array}$ & $\begin{array}{l}1.775^{*} \\
(1.16)\end{array}$ & $\begin{array}{l}-2.340^{*} \\
(0.63)\end{array}$ & $\begin{array}{l}1.060 \\
(1.04)\end{array}$ & $\begin{array}{l}-0.293^{*} \\
(1.21)\end{array}$ \\
\hline edumae $=4$ & $\begin{array}{l}-0.995 \\
(0.82)\end{array}$ & $\begin{array}{l}0.370^{*} \\
(0.88)\end{array}$ & $\begin{array}{l}1.582^{*} \\
(1.15)\end{array}$ & $\begin{array}{l}1.938^{*} \\
(1.20)\end{array}$ & $\begin{array}{l}-2.105^{*} \\
(0.63)\end{array}$ & $\begin{array}{l}1.262^{* *} \\
(1.05)\end{array}$ & $\begin{array}{l}0.573^{*} \\
(1.23)\end{array}$ \\
\hline edumae $=5$ & $\begin{array}{l}-0.804 \\
(0.84)\end{array}$ & $\begin{array}{l}0.784 \\
(0.89)\end{array}$ & $\begin{array}{l}2.186 * * * \\
(1.14)\end{array}$ & $\begin{array}{l}2.056^{* * *} \\
(1.18)\end{array}$ & $\begin{array}{l}-1.482^{* *} \\
(0.61)\end{array}$ & $\begin{array}{l}1.545 \\
(1.06)\end{array}$ & $\begin{array}{l}0.541^{*} \\
(1.22)\end{array}$ \\
\hline edumae $=6$ & $\begin{array}{l}-0.502 \\
(0.90)\end{array}$ & $\begin{array}{l}1.399 \\
(0.91)\end{array}$ & $\begin{array}{l}2.446^{* *} \\
(1.16)\end{array}$ & $\begin{array}{l}2.006^{* * *} \\
(1.20)\end{array}$ & $\begin{array}{l}-1.352^{* *} \\
(0.55)\end{array}$ & $\begin{array}{l}1.772^{*} \\
(1.09)\end{array}$ & $\begin{array}{l}1.140^{*} \\
(1.26)\end{array}$ \\
\hline edupai=1 & $\begin{array}{l}0.752 \\
(0.68)\end{array}$ & $\begin{array}{l}-0.146 \\
(0.75)\end{array}$ & $\begin{array}{l}-2.356^{* *} \\
(1.07)\end{array}$ & $\begin{array}{l}1.548 \\
(1.78)\end{array}$ & $\begin{array}{l}0.628 \\
(0.57)\end{array}$ & $\begin{array}{l}-0.710 \\
(0.95)\end{array}$ & $\begin{array}{l}-0.717 \\
(0.93)\end{array}$ \\
\hline edupai=2 & $\begin{array}{l}0.202 \\
(0.66)\end{array}$ & $\begin{array}{l}-0.106 \\
(0.75)\end{array}$ & $\begin{array}{l}-2.014^{* * *} \\
(1.06)\end{array}$ & $\begin{array}{l}1.438 \\
(1.77)\end{array}$ & $\begin{array}{l}-0.259 \\
(0.54)\end{array}$ & $\begin{array}{l}-0.571 \\
(0.93)\end{array}$ & $\begin{array}{l}0.056 \\
(1.02)\end{array}$ \\
\hline edupai=3 & $\begin{array}{l}-0.028 \\
(0.59)\end{array}$ & $\begin{array}{l}-0.092 \\
(0.74)\end{array}$ & $\begin{array}{l}-2.093^{* * *} \\
(1.07)\end{array}$ & $\begin{array}{l}1.308 \\
(1.77)\end{array}$ & $\begin{array}{l}0.502 \\
(0.46)\end{array}$ & $\begin{array}{l}-0.516 \\
(0.93)\end{array}$ & $\begin{array}{l}-0.101 \\
(0.84)\end{array}$ \\
\hline edupai=4 & $\begin{array}{l}-0.236 \\
(0.59)\end{array}$ & $\begin{array}{l}-0.178 \\
(0.76)\end{array}$ & $\begin{array}{l}-1.884^{* * *} \\
(1.09)\end{array}$ & $\begin{array}{l}1.474 \\
(1.78)\end{array}$ & $\begin{array}{l}0.435 \\
(0.44)\end{array}$ & $\begin{array}{l}-0.831 \\
(0.94)\end{array}$ & $\begin{array}{l}-0.140 \\
(0.85)\end{array}$ \\
\hline edupai=5 & $\begin{array}{l}-0.161 \\
(0.56)\end{array}$ & $\begin{array}{l}0.086 \\
(0.76)\end{array}$ & $\begin{array}{l}-1.947^{* * *} \\
(1.09)\end{array}$ & $\begin{array}{l}1.640 \\
(1.77)\end{array}$ & $\begin{array}{l}0.330 \\
(0.43)\end{array}$ & $\begin{array}{l}-0.758 \\
(0.94)\end{array}$ & $\begin{array}{l}0.382 \\
(0.81)\end{array}$ \\
\hline edupai $=6$ & $\begin{array}{l}0.162 \\
(0.63)\end{array}$ & $\begin{array}{l}-0.117 \\
(0.78)\end{array}$ & $\begin{array}{l}-1.755 \\
(1.11)\end{array}$ & $\begin{array}{l}1.194 \\
(1.79)\end{array}$ & $\begin{array}{l}0.000 \\
\text { (.) }\end{array}$ & $\begin{array}{l}-0.683 \\
(0.97)\end{array}$ & $\begin{array}{l}-0.399 \\
(0.79)\end{array}$ \\
\hline idademae & $\begin{array}{l}0.023 \\
(0.02)\end{array}$ & $\begin{array}{l}0.013 \\
(0.01)\end{array}$ & $\begin{array}{l}-0.022 \\
(0.02)\end{array}$ & $\begin{array}{l}0.008 \\
(0.01)\end{array}$ & $\begin{array}{l}0.000 \\
(0.02)\end{array}$ & $\begin{array}{l}0.023 \\
(0.02)\end{array}$ & $\begin{array}{l}-0.016 \\
(0.02)\end{array}$ \\
\hline idadepai & $\begin{array}{l}-0.005 \\
(0.02)\end{array}$ & $\begin{array}{l}0.002 \\
(0.01)\end{array}$ & $\begin{array}{l}0.040^{* * *} \\
(0.02)\end{array}$ & $\begin{array}{l}0.014 \\
(0.01)\end{array}$ & $\begin{array}{l}0.018 \\
(0.02)\end{array}$ & $\begin{array}{l}0.000 \\
(0.02)\end{array}$ & $\begin{array}{l}0.027 \\
(0.02)\end{array}$ \\
\hline racapai=2 & $\begin{array}{l}0.068 \\
(0.18)\end{array}$ & $\begin{array}{l}0.056 \\
(0.13)\end{array}$ & $\begin{array}{l}-0.265 \\
(0.21)\end{array}$ & $\begin{array}{l}0.425^{* *} \\
(0.18)\end{array}$ & $\begin{array}{l}0.150 \\
(0.25)\end{array}$ & $\begin{array}{l}-0.210 \\
(0.17)\end{array}$ & $\begin{array}{l}0.033 \\
(0.21)\end{array}$ \\
\hline racapai=3 & $\begin{array}{l}-0.003 \\
(0.20)\end{array}$ & $\begin{array}{l}0.096 \\
(0.11)\end{array}$ & $\begin{array}{l}-0.467^{*} \\
(0.17)\end{array}$ & $\begin{array}{l}0.116 \\
(0.21)\end{array}$ & $\begin{array}{l}-0.074 \\
(0.24)\end{array}$ & $\begin{array}{l}-0.116 \\
(0.16)\end{array}$ & $\begin{array}{l}-0.075 \\
(0.20)\end{array}$ \\
\hline racapai=4 & $\begin{array}{l}-0.145 \\
(0.43)\end{array}$ & $\begin{array}{l}-0.076 \\
(0.16)\end{array}$ & $\begin{array}{l}-0.485^{* *} \\
(0.23)\end{array}$ & $\begin{array}{l}-0.312 \\
(0.34)\end{array}$ & $\begin{array}{l}-0.330 \\
(0.29)\end{array}$ & $\begin{array}{l}-0.434^{* * *} \\
(0.23)\end{array}$ & $\begin{array}{l}-0.094 \\
(0.29)\end{array}$ \\
\hline racamae $=2$ & $\begin{array}{l}-0.300 \\
(0.33)\end{array}$ & $\begin{array}{l}0.358 \\
(0.29)\end{array}$ & $\begin{array}{l}0.800^{* *} \\
(0.33)\end{array}$ & $\begin{array}{l}0.503^{* * *} \\
(0.29)\end{array}$ & $\begin{array}{l}-0.664 \\
(0.53)\end{array}$ & $\begin{array}{l}-0.023 \\
(0.50)\end{array}$ & $\begin{array}{l}0.862^{* * *} \\
(0.48)\end{array}$ \\
\hline racamae $=3$ & $\begin{array}{l}-0.312 \\
(0.35)\end{array}$ & $\begin{array}{l}0.119 \\
(0.28)\end{array}$ & $\begin{array}{l}0.526^{* * *} \\
(0.30)\end{array}$ & $\begin{array}{l}0.447 \\
(0.30)\end{array}$ & $\begin{array}{l}-0.543 \\
(0.52)\end{array}$ & $\begin{array}{l}-0.214 \\
(0.50)\end{array}$ & $\begin{array}{l}0.480 \\
(0.48)\end{array}$ \\
\hline racamae $=4$ & $\begin{array}{l}-0.164 \\
(0.41)\end{array}$ & $\begin{array}{l}-0.145 \\
(0.31)\end{array}$ & $\begin{array}{l}0.788^{* *} \\
(0.34)\end{array}$ & $\begin{array}{l}0.263 \\
(0.43)\end{array}$ & $\begin{array}{l}-0.657 \\
(0.57)\end{array}$ & $\begin{array}{l}-0.200 \\
(0.51)\end{array}$ & $\begin{array}{l}0.852^{* * *} \\
(0.51)\end{array}$ \\
\hline H_Trab_Mae & $\begin{array}{l}0.307 \\
(0.61)\end{array}$ & $\begin{array}{l}-0.169 \\
(0.28)\end{array}$ & $\begin{array}{l}0.194 \\
(0.41)\end{array}$ & $\begin{array}{l}0.893^{* *} \\
(0.40)\end{array}$ & $\begin{array}{l}0.002 \\
(0.61)\end{array}$ & $\begin{array}{l}0.918^{* *} \\
(0.43)\end{array}$ & $\begin{array}{l}-0.053 \\
(0.54)\end{array}$ \\
\hline rural & $\begin{array}{l}-0.222 \\
(0.33)\end{array}$ & $\begin{array}{l}0.450 \\
(0.41)\end{array}$ & $\begin{array}{l}0.000 \\
\text { (.) }\end{array}$ & $\begin{array}{l}0.298 \\
(0.19)\end{array}$ & $\begin{array}{l}0.430 \\
(0.36)\end{array}$ & $\begin{array}{l}0.494 \\
(0.39)\end{array}$ & $\begin{array}{l}-0.639 \\
(0.61)\end{array}$ \\
\hline Constant & $\begin{array}{l}9.412^{*} \\
(0.65)\end{array}$ & $\begin{array}{l}6.555^{*} \\
(1.21)\end{array}$ & $\begin{array}{l}6.722^{*} \\
(0.72)\end{array}$ & $\begin{array}{l}3.350^{*} \\
(0.81)\end{array}$ & $\begin{array}{l}9.631^{*} \\
(0.59)\end{array}$ & $\begin{array}{l}6.957^{*} \\
(0.73)\end{array}$ & $\begin{array}{l}6.399 * \\
(1.19)\end{array}$ \\
\hline
\end{tabular}

Continuação 
Waleska de Fátima Monteiro - p.78

\begin{tabular}{|c|c|c|c|c|c|c|c|}
\hline Continuação & 0.0488 & 0.1393 & 0.1349 & 0.1255 & 0.0971 & 0.0684 & 0.1315 \\
\hline \multicolumn{8}{|l|}{ R2 Ajustado } \\
\hline Número de obs. & 583 & 2748 & 1227 & 1022 & 604 & 1102 & 505 \\
\hline $\mathrm{F}$ & 2.52 & 20.07 & 10.22 & 33.42 & 4.85 & 4.64 & 9.68 \\
\hline Prob $>F$ & 0.00 & 0.00 & 0.00 & 0.00 & 0.00 & 0.00 & 0.00 \\
\hline
\end{tabular}

